\title{
Genetic Differentiation in Moroccan Opuntia ficus-indica Cultivars Using Simple Sequence Repeat (SSR) Markers
}

\author{
Aissam EL FINTI ${ }^{1 *}$, Driss TALIBI ${ }^{1}$, Mohamed SEDKI ${ }^{2}$, Abdelhamid E. MOUSADIK ${ }^{1}$ \\ ${ }^{1} I b n$ Zohr University, Faculty of Science, Department of Biology, Laboratory of Biotechnology and Valorization of Natural Resources, CP 8106, Agadir 80000, \\ Morocco; elfintiaissam@yahoo.fr ("correspondingauthor);drissdesa@gmail.com;elmousadik@gmail.com \\ ${ }^{2}$ National Institute of Agronomic Research (INRA),B.P.124Inezgane,Agadir,Morroco; sidiki@yahoo.fr
}

\begin{abstract}
Estimation of genetic parameters at SSR loci can be applied for assessing the differences between cultivars or populations, either for variety distinction or the management of genetic resources. In this study, 13 Opuntia ficus-indica cultivars were analyzed using 10 SSR markers selected for studying the genetic diversity among these chosen cultivars. Over the 10 SSR markers, a total of 45 reproducible bands were scored with an average of 4.5 alleles/locus, while the observed heterozygosity (Ho) values of amplified loci ranged from 0.15 (SSR1) to 0.92 (SSR2 and SSR 11). Genetic distance analysis of the 13 cultivars showed a large genetic differentiation $(\mathrm{GST}=0.47)$ and high number of different groups. Most of the accessions were not found to be clustered according to their eco-geographical origin. In addition, each cultivar was characterized by its own multiallelic combination between loci. The results revealed the usefulness of SSR in understanding of genetic diversity in Moroccans Barbary fig cultivars, thus being helpful to set up rational decisions concerning the establishment of a national reference collection.
\end{abstract}

Keywords: Cactaceae, cactus pear, differentiation, microsatellite markers, preservation

\section{Introduction}

Cactus pear, or prickly pear, is a member of the Cactaceae family, and includes approximately 130 genera and 2,000 species (Reyes-Agüero et al., 2005). This plant species originated from arid and semi-arid regions of Mexico and was introduced into North Africa in the 16th century (Griffith, 2004). Opuntia and Nopalea are the most important genera due to their many applications (Valdez and Aranda, 1996). Within the genus Opuntia, O. ficus-indica is the most important for its production of edible fruits and cladodes, which are used as a vegetable and as animal forage. This particular cactus is a valuable resource especially during periods of drought when there is a shortage of other herbaceous plants for forage (Juárez and Passera, 2002). Cactus pear fruit is characterized by a high sugar content (12 to $17 \%$ ) and low acidity (Yahia and Mondragon, 2011). The fairly high sugar content and low acidity of the prickly pear fruit (Munoz-de-Chavez et al., 1995) make it very sweet and delicious. On the basis of fruit development, there are prickly pears of early, intermediate and late ripening, depending on the time required for full fruit development (Pimienta, 1994). Cacti are the most conspicuous and characteristic plants of warm arid regions. Cacti are remarkable for their diversity of growth forms and their ability to not only grow, but also to thrive, under environments recognized as stressful for most plant species. Cacti can be used to prevent soil erosion and act as an effective living fence for land reclamation, while functioning as a commercial crop with unique attributes (Le Houérou, 2000). Cacti have been exploited as a cheap, alternate source of food suitable for humans and feed for animals (Estrada-Luna et al., 2008).

In general, genetic improvement of crops can be accelerated when broad genetic diversity and the information of these genetic resources are available. Identifying cultivars is difficult when plants are in vegetative state, because there are few distinguishing features (Felker et al., 2006). Traditionally, markers based on morphological differences among individuals have been used to demonstrate the genetic variability (Sarutayophat et al., 2007). At present, molecular markers have been proved to be valuable tools in the characterization and evaluation of genetic diversity within and between species and identification of morphologically undistinguishable varieties.

Microsatellite or simple sequence repeat (SSR) has several advantages, such as simplicity of use, low cost and the use of small amount of plant material, and have proven to be powerful tools for fine-scale genetic characterizations, and yet generate large amount of data in a short period of time (Powell et al., 1996; Hokanson et al., 1998). These markers have been widely used in 
many crop species such as apple and flax as well as in Opuntia genus for detecting genetic diversity and relationships (Labra et al., 2003). Knowledge of genetic diversity and relationships between genotypes is particularly important for selection of parental genotypes, as well as for determining core collection for plant biodiversity conservation.

In this study, SSR analysis was carried out on 13 cultivars of the Opuntia ficus-indica collected from different localities of Morocco, to assess the genetic diversity among them, in the objective to have a suitable markers for the investigation of DNA polymorphism for genotyping the Moroccan cultivars, and to set up rational decisions concerning the establishment of a national reference collection.

\section{Materials and Methods}

\section{Plant material}

Thirteen Barbary fig cultivars, well representative of the Opuntia ficus-indica in Morocoo were used in this study. They were sampled from 13 localities from northeast to southwest of Morocco; the most well known regions sheltering various different morphological sorts of Barbary fig in the country (Table $1)$.

\section{Microsatellite analysis}

Cactus tissues usually have a high accumulation of polysaccharides (Wallace and Cota, 1996). Plants with high concentrations of polysaccharides usually yield DNA in low concentrations and of poor quality (Fang $e t$ al., 1992; Scott and Playford, 1996). A DNA method extraction technique for cacti, which helps to overcome the difficulties caused by mucilage, has been used. Thus, for each cultivar, an external slice of the cladode was taken for analysis. The cuticle was removed and a piece of about $1 \mathrm{~g}$ of the chlorenchym was cut using a scalpel and taking care to not include areolar meristems. Different isolation (Doyle and Doyle, 1987) protocols were experimented. The method that produced the highest DNA yield was ISOLATE Plant DNA Mini Kit. DNA concentrations were quantified by spectrophotometry and the intensity was compared with ethidium bromidestained DNA bands on $0.8 \%$ agarose gel. Uncut $\lambda$ DNA was used to adjust the final concentration of DNA to $100 \mathrm{ng} \mathrm{ml}^{-1}$ for use in PCR analysis. Opuntia specific microsatellite primers were obtained (Helsen et al., 2007) based on the isolated 16 polymorphic SSRs from O. echios. The 16 SSRs markers were adapted for O. ficusindica by optimizing, using gradient PCR to determine the optimum annealing temperature (Table 2). Amplifications were carried out separately for each SSR primer pair. The PCR reaction included $0,3 \mu \mathrm{M}$ forward primer and $0.3 \mu \mathrm{M}$ reverse primer, approximately $50 \mathrm{ng}$ of template DNA, $0.2 \mathrm{mM}$ dNTPs, 1x PCR buffer II, 2 $\mathrm{mM}$ magnesium chloride and $1 \mathrm{U}$ of GoTaq polymerase (Genome). PCR was performed at $95^{\circ} \mathrm{C}$ for $12 \mathrm{~min}$, followed by $35-40$ cycles of $95^{\circ} \mathrm{C}$ for $1 \mathrm{~min}, 53-55^{\circ} \mathrm{C}$ for $1 \mathrm{~min}$ (the annealing temperature was specific for each primer pair), and $72^{\circ} \mathrm{C}$ for $1.5 \mathrm{~min}$, and one final cycle of $72{ }^{\circ} \mathrm{C}$ for $15 \mathrm{~min}$. The PCR reactions were performed using thermocycler Gradient 96 and only reproducible products were taken after two repetitions. An aliquot of $5 \mu \mathrm{l}$ of PCR product (depending on the performance of amplification of each primer pair) was mixed with $10 \mu \mathrm{l}$ of formamide and denatured at $95^{\circ} \mathrm{C}$ for 5 min. The fragments obtained were resolved on a $7 \mathrm{M}$ urea $6 \%$

Table 1. Opuntia ficus-indica cultivars with their main area of origin in Morocco

\begin{tabular}{|c|c|c|c|c|c|c|}
\hline No. & Cultivar & Vernacular name & Code & Latitude W & Longitude $\mathrm{N}$ & Altitude (m) \\
\hline 1 & 'Ait Baha' & Achefri & $\mathrm{AB}$ & $30^{\circ} 10^{\prime}$ & $9^{\circ} 14^{\prime}$ & 222 \\
\hline 2 & 'Tafraout' & Achefri & TA & $29^{\circ} 53^{\prime}$ & $9^{\circ} 00^{\prime}$ & 1215 \\
\hline 3 & 'Sidi-Ifni M' & Moussa & SM & $29^{\circ} 20^{\prime}$ & $10^{\circ} 08^{\prime}$ & 66 \\
\hline 4 & 'Sidi-Ifni A' & Aissa & SA & $29^{\circ} 20^{\prime}$ & $10^{\circ} 08^{\prime}$ & 65 \\
\hline 5 & “Tamri" & Achefri & TR & $30^{\circ} 40^{\prime}$ & $9^{\circ} 52^{\prime}$ & 36 \\
\hline 6 & ‘Ben Guerir’ & Aknari & $\mathrm{BG}$ & $32^{\circ} 30^{\prime}$ & $7^{\circ} 53^{\prime}$ & 434 \\
\hline 7 & 'Chaoun' & Zaaboul & $\mathrm{CH}$ & $35^{\circ} 08^{\prime}$ & $5^{\circ} 16^{\prime}$ & 555 \\
\hline 8 & 'Hoceima' & Delahia & $\mathrm{HO}$ & $30^{\circ} 57^{\prime}$ & $4^{\circ} 17^{\prime}$ & 1100 \\
\hline 9 & 'Nador' & Hndiya & NA & $35^{\circ} 15^{\prime}$ & $3^{\circ} 40^{\prime}$ & 70 \\
\hline 10 & 'Berkane' & Hndiya & $\mathrm{BR}$ & $34^{\circ} 51^{\prime}$ & $2^{\circ} 36^{\prime}$ & 200 \\
\hline 11 & 'Meknès' & Hndiya & MK & $33^{\circ} 47^{\prime}$ & $5^{\circ} 29^{\prime}$ & 700 \\
\hline 12 & 'Mohammedia' & Hndiya & $\mathrm{MH}$ & $33^{\circ} 41^{\prime}$ & $7^{\circ} 19^{\prime}$ & 64 \\
\hline 13 & 'Safi' & Aknari & SF & $32^{\circ} 40^{\prime}$ & $9^{\circ} 04^{\prime}$ & 56 \\
\hline
\end{tabular}


382

Table 2. SSR primer pairs used for Opuntia ficus-indica DNA amplification

\begin{tabular}{|c|c|c|c|c|c|}
\hline Oligo code & Forward and reverse primer & Size range $(\mathrm{bp})$ & GC \% & Tm Obs. $\left[{ }^{\circ} \mathrm{C}\right]$ & Tm Exp. $\left[{ }^{\circ} \mathrm{C}\right]$ \\
\hline \multirow[t]{2}{*}{ SSR11 } & F: 5' ATC TCA TTG TAT CAT CTA TTT CCT G 3' & $127-152$ & $50 \%$ & 57.3 & 51.4 \\
\hline & R: 5' GTT TAG CAC AAA GAC ACT TCA TCG 3' & & $50 \%$ & 57.3 & 51.4 \\
\hline \multirow[t]{2}{*}{ SSR 13} & F: 5'ACC GCC ATC ACC AGC TAT C 3' & $136-178$ & $45 \%$ & 55.3 & 53.2 \\
\hline & R: 5' GTT TCT CAC CCA CAA TTC CAA ACC 3' & & $45 \%$ & 55.3 & 53.2 \\
\hline \multirow[t]{2}{*}{ SSR 15} & F: 5' CCA TCT ACT TCC CAC TTT GC $3^{\prime}$ & $100-126$ & $32 \%$ & 56.4 & 53.2 \\
\hline & R: 5' GTT TCT CCT GTG TTT CTC TGT GCT C 3' & & $41.7 \%$ & 59.3 & 53.2 \\
\hline \multirow[t]{2}{*}{ SSR 1} & F : 5' CTA GGC TTC ATC CCA CAT TAG G 3' & $147-185$ & $47.4 \%$ & 54.5 & 53.2 \\
\hline & R: 5' TCC AAA TTC ACC TCC TCT GC $3^{\prime}$ & & $47.8 \%$ & 60.6 & 53.2 \\
\hline \multirow[t]{3}{*}{ SSR 2} & F : 5' TAA TCT TAT TCT CAG GTC AGT TAC 3' & 226-294 & $57.9 \%$ & 58.8 & 58.1 \\
\hline & R: 5' GGT ATC TTG TTC GTT CG 3' & & $45.8 \%$ & 61.0 & 58.1 \\
\hline & R: 5' CCA ACC ATA CCA ACT GTA CTG AC 3' & & $37.5 \%$ & 57.6 & 58.1 \\
\hline \multirow[t]{2}{*}{ SSR 4} & F : 5' CCT ACA CCT GCT GCC AAT C 3' & $110-138$ & $50 \%$ & 57.3 & 60.8 \\
\hline & R: 5' CGA GAC AAA CAT CAG AGG AG 3' & & $33.3 \%$ & 52.0 & 60.8 \\
\hline \multirow[t]{2}{*}{ SSR 5} & F : 5' CCA AAT ACC CAG CCC ATA C $3^{\prime}$ & $247-301$ & $55 \%$ & 59.4 & 60.8 \\
\hline & R: 5' CGA GAA CCT AAC TTC CGA TG 3' & & $55 \%$ & 59.4 & 60.8 \\
\hline \multirow[t]{2}{*}{ SSR 6} & F : 5' GTG AGT GCC CAG ATG AAA CT 3' & $317-344$ & $45 \%$ & 55.3 & 63.5 \\
\hline & R: : $5^{\prime}$ TCC TCA ACT TTA TTG TAG CAA GAG 3' & & $40 \%$ & 55.3 & 63.5 \\
\hline \multirow[t]{2}{*}{ SSR 7} & F: GCTTTGAAATGTCTTGTGTGAATG & $134-162$ & $50 \%$ & 57.3 & 63.5 \\
\hline & R: AGTCCTGGGAATCCTCAACC & & $48 \%$ & 63.0 & 63.5 \\
\hline \multirow[t]{2}{*}{ SSR 8} & F: TGCAGTCAGGTTTCTCATTGTC & $196-218$ & $57.9 \%$ & 58.8 & 69.7 \\
\hline & R: GCCCAACTCTTACССТСТCC & & $50 \%$ & 57.3 & 69.7 \\
\hline
\end{tabular}

denaturing polyacrylamide gel $17 \times 21 \mathrm{~cm}$ run at a constant power of $60 \mathrm{~W}$. Gels were stained with silver nitrate and fragment sizes were determined by comparison to a $10 \mathrm{bp}$ DNA ladder (Invitrogen).

\section{Statistical analysis}

The following parameters were calculated for every locus, using software FSTAT (Version 2.9.3.2) (Goudet, 2001) and Genepop (Version 4) (Raymond and Rousset, 1995): the distribution of allele frequencies, the number of alleles, the observed heterozygosity $(\mathrm{Ho})$, the expected population heterozygosity $(H s)$, the expected total heterozygosity $(H t)$ and the proportion among cultivars differentiation (GST) (Nei, 1978). Genepop was used to test pairwise linkage equilibriums at all loci over any two groups, and to calculate the pairwise genetic differentiation FST (Weir and Cockerham, 1984). The software Phylip 3.5c (Felsenstein, 1993) was used to determine Nei's standard genetic distance $(D s)$ (Nei, 1972) and to draw a UPGMA tree and a neighborjoining tree (Saitou and Nei, 1987) based on the allele frequency data. An FCA (Factorial correspondence analysis) was used to illustrate dissimilarity between

Table 3. Genetic parameters estimated for 10 SSR loci studied in 13 Opuntia ficus-indica cultivars

\begin{tabular}{lcccccc}
\hline $\begin{array}{c}\text { SSR } \\
\text { code }\end{array}$ & $\begin{array}{c}\text { Number of } \\
\text { alleles }\end{array}$ & Ho & Hs & Ht & Gst & Fis \\
\hline SSR11 & 4 & 0.92 & 0.46 & 0.67 & 0.31 & -0.37 \\
SSR5 & 3 & 0.69 & 0.34 & 0.53 & 0.35 & -0.29 \\
SSR7 & 7 & 0.84 & 0.42 & 0.72 & 0.41 & -0.16 \\
\hline SSR8 & 3 & 0.84 & 0.42 & 0.60 & $\mathbf{0 . 3 0}$ & -0.39 \\
SSR15 & 2 & 0.28 & 0.14 & $\mathbf{0 . 4 0}$ & 0.65 & 0.30 \\
SSR2 & $\mathbf{8}$ & $\mathbf{0 . 9 2}$ & $\mathbf{0 . 4 6}$ & $\mathbf{0 . 8 0}$ & 0.42 & -0.14 \\
\hline SSR1 & 3 & $\mathbf{0 . 1 5}$ & $\mathbf{0 . 0 7}$ & 0.64 & $\mathbf{0 . 8 8}$ & 0.76 \\
SSR13 & 5 & 0.84 & 0.42 & 0.74 & 0.43 & -0.13 \\
\hline SSR6 & 6 & 0.84 & 0.42 & 0.75 & 0.43 & -0.12 \\
SSR4 & 4 & 0.76 & 0.38 & 0.74 & 0.48 & -0.03 \\
Mean & 4,5 & 0,78 & 0,35 & 0,66 & 0,466 & $-0,057$ \\
\hline & & & & & &
\end{tabular}

cultivars based on the dissimilarity of their allelic variability.

\section{Results and Discussion}

Ten SSR loci were selected from the 16 SSR markers tested and have been developed for optimal annealing temperature (Table 2). The molecular profile of SSR showed their power discriminating between the 13 cultivars studied (e.g. SSR8 primer; Fig. 1). For each polyacrylamide gel electrophoresis (PAGE) and each primer, bands were coded in terms of their alleles with corresponding molecular weight. A total of 45 alleles were detected within the 13 cultivars (Table 3 ). The number of alleles per locus ranged from 2 for SSR15, to 8 for SSR2, with an average of 4.5 alleles per locus.

The total number of alleles was higher in 'Ait Baha' and 'Sidi Ifni Aissa' (19 alleles), but it was relatively lower in 'Tafraout' cultivar, with 16 alleles (Table 5). Moreover, several unique alleles were observed in 'Hoceima' cultivar (SSR5-290bp/265bp), 'Chaoun' (SSR2-289bp; SSR1160bp) and 'Ait Baha' (SSR13-150bp). These unique alleles may be considered effective genetic markers for cultivars identification.

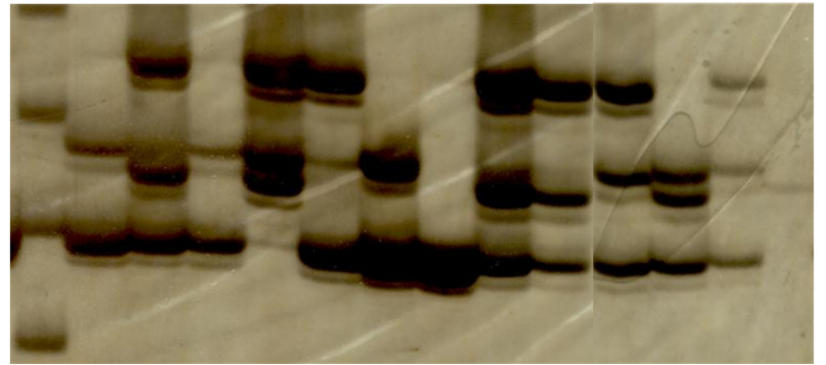

Fig. 1. Segregation of alleles of an SSR8 marker observed on $6 \%$ polyacrylamide gel in Opuntia ficus-indica cultivars. Lanes 1 to 13 correspond to accessions listed in Table 1; Lane M, molecular mass marker (10 bp DNA ladder) 
Table 4. FST value between pairs of cultivars, calculated with 10 SSR loci (All values were highly significant at $\mathrm{p}<1 \%$ )

\begin{tabular}{|c|c|c|c|c|c|c|c|c|c|c|c|c|}
\hline & TA & SM & SA & TR & BG & $\overline{\mathrm{CH}}$ & HO & NA & $\overline{\mathrm{BE}}$ & $\mathrm{ME}$ & M0 & $\mathrm{Si}$ \\
\hline "Ait Baha" & 0.50 & 0.25 & 0.57 & 0.50 & 0.55 & 0.44 & 0.54 & 0.56 & 0.44 & 0.54 & 0.56 & 0.59 \\
\hline "Tafraout" & & 0.36 & 0.54 & 0.48 & 0.48 & 0.54 & 0.61 & 0.57 & 0.63 & 0.59 & 0.59 & 0.54 \\
\hline "Sidi-Ifni M" & & & 0.46 & 0.43 & 0.48 & 0.421 & 0.53 & 0.56 & 0.52 & 0.56 & 0.53 & 0.48 \\
\hline “Sidi-Ifni A" & & & & 0.44 & 0.43 & 0.60 & 0.50 & 0.54 & 0.52 & 0.57 & 0.54 & 0.43 \\
\hline “Tamri” & & & & & 0.37 & 0.43 & 0.37 & 0.43 & 0.45 & 0.44 & 0.38 & 0.43 \\
\hline "Ben Guerir" & & & & & & 0.55 & 0.48 & 0.48 & 0.54 & 0.52 & 0.50 & 0.48 \\
\hline "Chaoun" & & & & & & & 0.48 & 0.46 & 0.56 & 0.57 & 0.59 & 0.56 \\
\hline "Hoceima" & & & & & & & & 0.43 & 0.46 & 0.48 & 0.57 & 0.57 \\
\hline "Nador" & & & & & & & & & 0.52 & 0.50 & 0.48 & 0.53 \\
\hline "Berkane" & & & & & & & & & & 0.44 & 0.36 & 0.52 \\
\hline "Meknès" & & & & & & & & & & & 0.48 & 0.55 \\
\hline "Mohamedia" & & & & & & & & & & & & 0.44 \\
\hline
\end{tabular}

Table 5 . Allelic variability among cultivars and total number of alleles revealed by 10 SSR loci

\begin{tabular}{|c|c|c|}
\hline Cultivar & $\begin{array}{l}\text { No. of } \\
\text { alleles }\end{array}$ & Allelic combination between loci \\
\hline "Ait Baha" & 19 & 011010001100111010100100100110110010101 \\
\hline "Ben Guerir" & 17 & 001110001100111010100001001010100110010 \\
\hline "Berkane" & 17 & 101010001100101110100001101010011000010 \\
\hline "Chaoun" & 17 & 101010001100110000100001101010100110101 \\
\hline "Hoceima" & 18 & 001110001100101100100001101010100110110 \\
\hline "Meknès" & 18 & 001110001100111000100001101010011010110 \\
\hline "Mohammedia" & 17 & 101010000011001011010000101010011010110 \\
\hline "Nador" & 18 & 001110001100101100100001100011100110110 \\
\hline "Sidi-Ifni Aissa" & 19 & 101010000011011011010000101010011010010 \\
\hline "Safi" & 17 & 001110001100101110001010010011110010110 \\
\hline "Sidi-Ifni Moussa" & 18 & 011010001100111010100100001010110010101 \\
\hline “Tafraout” & 16 & 000110001100111010100100000001110011001 \\
\hline “Tamri" & 17 & 101000110100111000100100001010110010110 \\
\hline
\end{tabular}

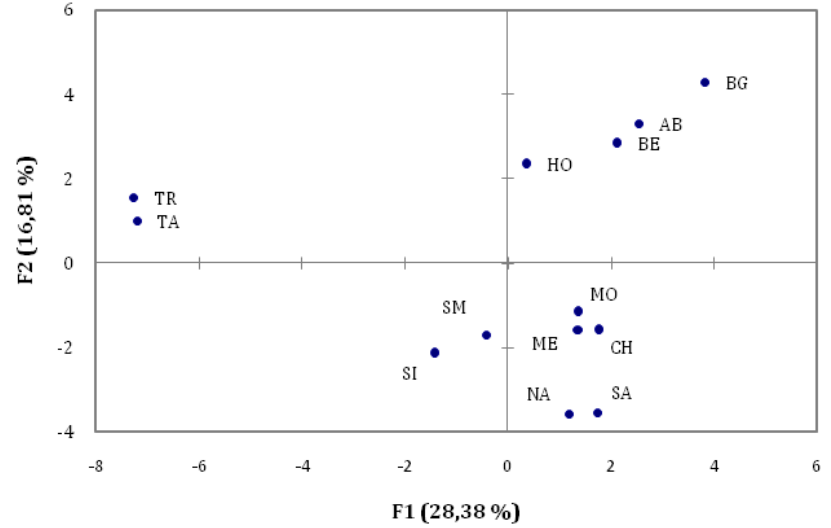

Fig. 2. Opuntia cultivars projected in the factorial plan based on dissimilarity of their allelic

The parameters of genetic diversity calculated for each loci (10 SSR primers) and their average (Table 3) for all the 13 cultivars studied, overall showed an excess of heterozygosity ( $\mathrm{Ho}>\mathrm{Hs}$ ), with SSR2 contributing most to the heterozygosity genotypes, which was consistent with the high number of alleles detected (8). In contrast, with three alleles in total, SSR1 marker was lower in heterozygous structures. However, SSR1 contributed most to the genetic differentiation. Furthermore, all ten SSR markers contributed in genetic differentiation of the 13 cultivars studied. This shows the low exchange of gene flow between cultivars, and reinforces the idea of isolation under the anthropogenic effect. In fact, cultivars generally correspond to

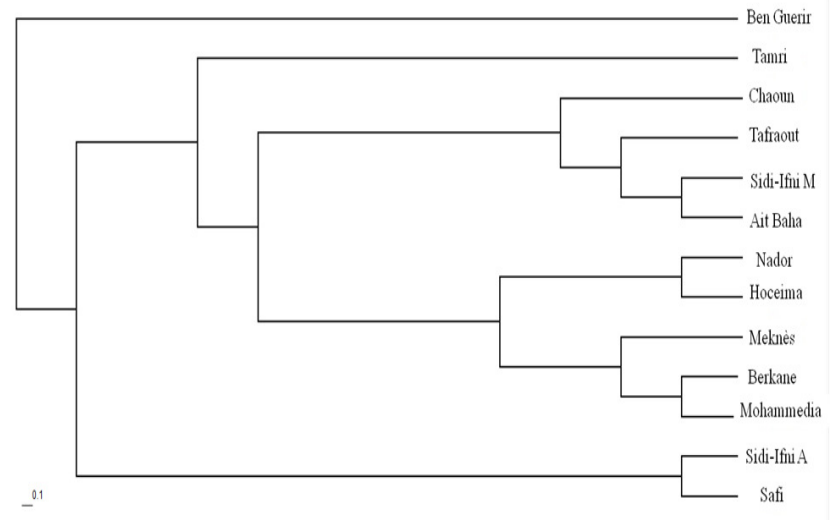

Fig. 3. UPGMA dendrogram of 13 local cactus cultivars based on SSR markers

plantations multiplied from the same genotype or clone. The coefficients of differentiation calculated (FST) between cultivars clearly illustrated the high level of genetic differentiation, which varied between 0.36 and 0.61 ,except for FST (0.25) calculated between 'Ait Baha' and 'Sidi Ifni Moussa' (Table 4).

The analysis of allelic combination between loci showed a clear separation between the 13 cultivars studied (Table 5). This variability depends on the number of mutations detected. Their projection (FCA) (Fig. 2) showed that all cultivars were represented, with four sub-groups (1: 'Tafraout' and 'Tamri'; 2: 'Hoceima', 'Berkane', 'Ait Baha' and 'Ben Guerir'; 3: 'Safi' and 'Sidi Ifni Moussa'; 4: 'Nador', 'Sidi Ifni Aissa Chaoun', 
384

'Meknes' and 'Mohammedia'), but have no structure in relation to their geographic origin. The results compared with those found in the literature show that the RAPD markers (El Finti et al., 2013) also allowed differentiation between the same Moroccans cultivars studied without systematic grouping according to geographical proximity. However, the SSR markers (GST $=0.46$ ) appear more discriminating than RAPD (GST $=0.29)$. Nevertheless, these two types of markers (RAPD and SSR) show the absence of a systematic grouping according to geographical proximity of studied cultivars. On the other hand, the dendrogram (Fig. 3) illustrates cultivars clustering independently from the region of origin, since the genotypes housed in all the groups did not significantly diverge, though originating from different localities (Table 1).

The conservation of genetic resources of any species and the establishment of a catalogue describing local varieties require knowledge of their genetic diversity and the genetic relationships between related species. The availability of different molecular tools to analyze genetic diversity among Opuntia cultivars makes it possible to give order to the large array of synonyms, but the large morphological variation within different species suggest that phenotypical characteristics will not serve to produce a stable classification. The difficulties of morphological interpretation have led to publication of a large number of binomials, many of which are synonyms or false attributions (Gibson, 1986). Therefore, the purpose is set to establish the usefulness of SSR in the identification of cultivars and to define the relationships among Moroccan Barbary fig cultivars.

The current results showed that SSR markers have a good estimation of the genetic diversity among several Moroccan Opuntia ficus-indica cultivars. The high level of genetic variation could be explained by the species outcrossing, breeding system and the persistence of multiple individuals through generations from large populations before fragmentation (Young et al., 1996). The high genetic differentiation among cultivars might be the consequence of population isolation due to habitat destruction from the last few decades as suggested by Schoenenberger and Dimanche (1995).

In fact, some primers were tested leading to polymorphic bands reaching 45 polymorphic bands that is considerably important comparing to other results reported by Labra et al. (2003) using five SSR primers. The UPGMA dendrogram showed the distribution of cultivars independently from their geographic origin, and closeness among cultivars. The homonyms assigned to Moroccans cultivars appear to have a good identification of the geographical origin (e.g. 'Delahia', 'Moussa', 'Aissa').

At the basis of morphological traits, it can easily be observed that in all Opuntia accessions, only two varieties were characterized by the presence or absence of spines. According to the work of Kiesling (1998), the absence of spines could be considered as a secondary trait selected by farmers in domesticated accessions. In fact, all varieties cultivated are spines free, to facilitate fruit harvesting. On the basis of these considerations, it must be underlined that spine-free trait, the main morphological difference between accessions (Britton and Rose, 1919), should not be considered as a parameter in Opuntia taxonomy. Up to now, phenotypic diversity in Moroccan Barbary fig cultivars has not been studied widely.

\section{Conclusions}

The present study indicated the amount of variability and highlighted the strong difference among cultivars. However, due to the fruit quality characteristics, this is the important resource for breeding and improving cultivars for diverse demands of consumers in the world. The current results highlight the importance of SSR markers as an efficient tool to analyze genetic variability within Moroccan Opuntia cultivars and recommend the breeding potential of this species to start improvement and conservation programs. The development of a core collection could facilitate easier access to Barbary fig genetic resources, enhance their use in crop improvement programs and simplify the gene bank management.

\section{References}

Britton N, Rose J (1919). The Cactaceae. Washington DC, Carnegie Institution.

Doyle J, Doyle J (1987). A rapid DNA isolation procedure for small quantities of fresh leaf tissue. Phytochemical Bulletin 19:11-15.

El Finti A, Belayadi M, El Boullani R, Msanda F, El Mousadik A (2013). Genetic structure of cactus pear (Opuntia ficusindica) in a Moroccan collection. Atlas Journal of Plant Biology 1(2):24-28.

Estrada-Luna AA, Martínez-Hernández JJ, Torres-Torres ME, Chablé-Moreno $F$ (2008). In vitro micropropagation of the ornamental prickly pear cactus Opuntia lanigera SalmDyck and effects of sprayed GA 3 after transplantation to ex vitro conditions. Scientia Horticulturae 117(4):378385.

Fang G, Hammar S, Grumet R (1992). A quick and inexpensive method for removing polysaccharides from plant genomic DNA. Biotechniques 13 (1):52-54.

Felker P, Paterson A, Jenderek MM (2006). Forage potential of clones maintained by the USDA, National Plant Germplasm System (NPGS) collection. Crop Science 46 (5):2161-2168.

Felsenstein J (1993). Phylogenetic inference package (PHYLIP), version 3.5. University of Washington, Seattle.

Gibson AC, Park S Nobel (1986). The cactus primer. Cambridge, Harvard University Press.

Goudet J (2001). FSTAT, version 2.9.3, A program to estimate and test gene diversities and fixation indices. Lausanne University, Lausanne, Switzerland.

Griffith MP (2004). The origins of an important cactus crop, Opuntia ficus-indica (Cactaceae): new molecular evidence. American Journal of Botany 91(11):1915-1921.

Helsen P, Verdyck P, Tye A, Desender K, van Houtte N, van Dongen S (2007). Isolation and characterization of 
polymorphic microsatellite markers in Galapagos prickly pear (Opuntia) cactus species. Molecular Ecology Notes $7(3): 454-456$.

Hokanson S, Szewc-McFadden A, Lamboy W, McFerson J (1998). Microsatellite (SSR) markers reveal genetic identities, genetic diversity and relationships in a Malus $\times$ domestica Borkh. core subset collection. TAG Theoretical and Applied Genetics 97(5):671-683.

Juárez MC, Passera CB (2002). In vitro propagation of Opuntia ellisiana Griff. and acclimatization to field conditions. Biocell 26(3):319-324.

Kiesling R (1998). Origen, domesticación y distribución de Opuntia ficus-indica. Journal of the Professional Association for Cactus Development 3:50-59.

Labra M, Grassi F, Bardini M, Imazio S, Guiggi A, Citterio S, Banfi E, Sgorbati S (2003). Genetic relationships in Opuntia Mill. genus (Cactaceae) detected by molecular marker. Plant Science 165(5):1129-1136.

Le Houérou HN (2000). Utilization of fodder trees and shrubs in the arid and semiarid zones of West Asia and North Africa. Arid Soil Research and Rehabilitation 14(2):101-135.

Munoz-de-Chavez M, Chavez A, Valles A, Roldan J (1995). Plants in human nutrition. World Review of Nutrition and Dietetics 77:175-181.

Nei M (1972). Genetic distance between populations. American Naturalist pp 283-292.

Nei M (1978). Estimation of average heterozygosity and genetic distance from a small number of individuals. Genetics 89(3):583-590.

Pimienta-Barrios E (1994). Prickly pear (Opuntia spp.): A valuable fruit crop for the semi-arid lands of Mexico. Journal of Arid Environments 28(1):1-11.

Powell W, Morgante M, Andre C, Hanafey M, Vogel J, Tingey $S$, Rafalski A (1996). The comparison of RFLP, RAPD, AFLP and SSR (microsatellite) markers for germplasm analysis. Molecular Breeding 2(3):225-238.
Raymond M, Rousset F (1995). GENEPOP (version 1.2): population genetics software for exact tests and ecumenicism. Journal of Heredity 86(3):248-249.

Reyes-Agüero JA, Aguirre-Rivera JR, Hernández HM (2005). Systematic notes and a detailed description of Opuntia ficus-indica (L.) MILL. (Cactacteae). Agrociencia 39:395408.

Saitou N, Nei M (1987). The neighbor-joining method: a new method for reconstructing phylogenetic trees. Molecular Biology and Evolution 4(4):406-425.

Sarutayophat T, Nualsri C, Santipracha Q, Saereeprasert V (2007). Characterization and genetic relatedness among 37 yardlong bean and cowpea accessions based on morphological characters and RAPD analysis. Songklanakarin Journal of Science and Technology (Thailand) 29 (3):591-600.

Schoenenberger A, Dimanche P (1995). La végétation forestière primitive et son état actuel. Essai de synthèse sur la végétation et la phyto-écologie tunisiennes II et III: Le milieu physique et la végétation, IOR, Tunisie pp 209-278.

Scott K, Playford J (1996). DNA extraction technique for PCR in rain forest plant species. Biotechniques 20(6):974, 977.

Valdez CAF, Aranda G (1996). Opuntia-based ruminant feeding systems in Mexico. Grana 56, Livestock Feed Resources within Integrated Farming Systems pp 459-466.

Wallace RS, Cota JH (1996). An intron loss in the chloroplast generpoC1 supports a monophyletic origin for the subfamily Cactoideae of the Cactaceae. Current Genetics 29(3):275-281.

Weir BS, Cockerham CC (1984). Estimating F-statistics for the analysis of population structure. Evolution pp 13581370.

Yahia EM, Mondragon-Jacobo C (2011). Nutritional components and anti-oxidant capacity of ten cultivars and lines of cactus pear fruit (Opuntia spp.). Food Research International 44(7):2311-2318. 